\title{
Interactions among density, climate, and food web effects determine long-term life cycle dynamics of a key copepod
}

\author{
Saskia A. Otto ${ }^{1,2, *}$, Georgs Kornilovs ${ }^{3}$, Marcos Llope ${ }^{4}$, Christian Möllmann ${ }^{2}$ \\ ${ }^{1}$ Stockholm Resilience Centre, Stockholm University, Kräftriket 2b, 10691 Stockholm, Sweden \\ ${ }^{2}$ Institute for Hydrobiology and Fisheries Science, Center for Earth System Research and Sustainability (CEN), \\ KlimaCampus, University of Hamburg, Grosse Elbstrasse 133, 22767 Hamburg, Germany \\ ${ }^{3}$ Department of Fish Resources Research, Institute of Food Safety, Animal Health and Environment, Daugavgrivas str. 8, \\ 1048 Riga, Latvia \\ ${ }^{4}$ Instituto Español de Oceanografía (IEO), Centro Oceanográfico de Cádiz, Puerto Pesquero, Muelle de Levante s/n, \\ PO Box 2609, 11006 Cádiz, Andalucía, Spain
}

\begin{abstract}
Increasing pressure on animal populations through climate change and anthropogenic exploitation fuel the need to understand complex life cycle dynamics of key ecosystem species and their responses to external factors. Here, we provide a novel, integrative study on the long-term population dynamics of Pseudocalanus acuspes, a key species in the Baltic Sea, explicitly considering its distinct life-history stages, and testing for linear, non-linear, and non-additive climate and food web effects. Based on a unique data set of stage-specific abundance covering almost 5 decades of sampling (1960 to 2008, with 1408 samples), we use generalized additive modeling (GAM) and its respective non-additive threshold (TGAM) formulation to test for (1) density effects on subsequent life-history stages within the internal life cycle, (2) the effect of exogenous bottom-up (i.e. hydro-climatic) and top-down (i.e. predation) pressures, and (3) changes between bottom-up and top-down regulation. We show that linear density effects are always present, explaining a high proportion of interannual variability, while effects of external pressures are nonlinear or non-additive and strongly stage- and season-specific. In general, younger stages of $P$. acuspes are more affected by atmospheric winter conditions and water temperature, whereas older stages are influenced by conditions of deepwater salinity and predation pressure. These bottom-up processes, however, are not necessarily stable, and can depend on the level of top-down predation pressure. Our study demonstrates the complex and non-stationary interplay between internal and external factors regulating long-term animal population dynamics.
\end{abstract}

KEY WORDS: Life cycle dynamics · Climate change $\cdot$ Internal and external effects $\cdot$ Generalized additive modeling $\cdot$ Top-down vs. bottom-up control $\cdot$ Non-additive effects $\cdot$ Zooplankton

Resale or republication not permitted without written consent of the publisher

\section{INTRODUCTION}

Increasing pressure on aquatic animal populations through climate change and anthropogenic exploitation is of much ecological concern for the functioning of ecosystems and their ability to provide services to humanity (Worm et al. 2006, Burrows et al. 2011, Car- dinale et al. 2012, Doney et al. 2012). Crucially important for mitigating these global change effects is the understanding of the complex life cycle dynamics of key ecosystem species and their response to external pressures (Kingsolver et al. 2011). External drivers can have linear or non-linear effects on population trajectories, and frequently interact at particular 
spatial or temporal scales (Bjørnstad \& Grenfell 2001). Furthermore, long-term studies on terrestrial and aquatic species suggest combined effects of nonlinear population dynamic processes and exogenous drivers such as food, temperature, or snowmelt (e.g. Arcese \& Smith 1988, Dingsør et al. 2007, Boggs \& Inouye 2012). Interestingly, the interactions between driving variables are often non-additive, i.e. the effect of one variable changes under contrasting states of a control variable, and are often best represented by statistical threshold models (Ciannelli et al. 2004, Llope et al. 2011).

In species with complex life cycles, such as marine pelagic copepods, the various life-history stages usually vary in size and shape, and therefore also in their ability to acquire resources and their response to environmental conditions (Twombly et al. 2007, Kingsolver et al. 2011). Biotic and abiotic bottom-up effects on vital rates such as mortality, fecundity, and growth are hence likely stage-specific. Furthermore, morphological differences between life-history stages may lead to differing vulnerability to top-down predation pressure (Brooks \& Dodson 1965). Eventually, the effects of external drivers on a specific life stage may propagate through the life cycle and indirectly affect subsequent life stages (Benton et al. 2006). To fully understand the long-term population dynamics of animal populations, it is hence crucial to consider the various external drivers affecting each lifehistory stage and how stage-specific effects propagate through the life cycle - a task frequently hindered by limited or even a lack of long-term data series.

Marine zooplankton species have complex life cycles, with up to 12 different life-history stages (Banse 1995). Copepods are, both in terms of numbers and biomass, the dominating zooplankton group, and play a major role in the flow of matter and energy in pelagic food webs (Miller 2005). Traditionally, marine zooplankton is considered as being bottom-up-controlled, and hence may serve as suitable indicators of the effect of climate on the ocean, unbiased by anthropogenic effects at the top of food webs (Hays et al. 2005). Consequently, a multitude of studies have been published that relate long-term zooplankton dynamics to hydro-climatic variables (e.g. Fromentin \& Planque 1996, Möllmann et al. 2000, Beaugrand 2003, Persson et al. 2012).

Recently, changes in top-predator abundance, frequently induced by overfishing (Frank et al. 2007, Strong \& Frank 2010), and the cascading effects on lower trophic levels, have been shown for many marine ecosystems (Daskalov et al. 2007, Casini et al.
2008, Möllmann \& Diekmann 2012). These trophic cascade studies show that planktonic trophic levels are affected by changes at the top of the food web and hence indicate top-down control of marine zooplankton by planktivores (Möllmann et al. 2008, Baum \& Worm 2009). However, the prevailing modes of trophic regulation within ecosystems can also change temporally and spatially (Frank et al. 2006, Hunt \& McKinnell 2006), with climate variability and change as a main trigger (Litzow \& Ciannelli 2007). Hence, a few recent studies on long-term changes in zooplankton included predation effects and especially tested for non-additive dynamics, i.e. shifts between bottom-up and top-down controls (Stige et al. 2009, Llope et al. 2011). These studies, though, lack a comprehensive investigation of the complex stage-specific life cycle dynamics in response to a multitude of interacting external drivers.

The genus Pseudocalanus is one of the dominant zooplanktonic animals in the world ocean (Corkett \& McLaren 1978). In the Baltic Sea, $P$. acuspes is a key ecosystem player as an important food source for fish predators (Möllmann et al. 2003, 2008), and is part of a recent ecosystem regime shift (Möllmann et al. 2009). Here, we provide a novel, integrative study on the long-term population dynamics of this key species, explicitly considering its complex life cycle, and testing for linear, non-linear, and non-additive climate and food web effects. Based on a unique data set of seasonal stage-specific abundance covering almost 5 decades of sampling (1960 to 2008, with 1408 samples), we use generalized additive modeling (GAM) and its respective non-additive threshold (TGAM) formulation (Ciannelli et al. 2004) to test for (1) density effects on subsequent life-history stages within the internal life cycle, (2) the effect of exogenous bottom-up (i.e. hydro-climatic) and top-down (i.e. predation) pressures, and (3) changes between bottom-up and top-down regulation. We show that effects of external pressures are strongly stagespecific and propagate through the life cycle. Our study demonstrates the complex and non-stationary interplay between internal and external factors regulating long-term animal population dynamics.

\section{METHODS}

\section{The model organism: Pseudocalanus acuspes}

We investigated the long-term population dynamics of Pseudocalanus acuspes in the Baltic Sea (Fig. S1 in the Supplement at www.int-res.com/articles/suppl 
/m498p073_supp.pdf). Calanoid copepods such as $P$. acuspes have complex life cycles, developing through 11 larval stages (6 nauplii and 5 copepodite stages) to the adult stage. In contrast to other Pseudocalanus spp. congeners, the life cycle of Baltic $P$. acuspes is characterized by an annual generation, with a reproductive peak in spring, usually around May (Renz \& Hirche 2006). Although a small fraction of the egg-carrying population is able to reproduce year round (Renz et al. 2007), a stable progression of the stage structure is observed (see our Fig. 1a). This life cycle characteristic of $P$. acuspes allowed us to model internal density effects, which we define here as the effect of one stage's abundance on successive stages.

\section{Data}

Abundance $\left(\mathrm{n} \mathrm{m}^{-3}\right)$ data for Pseudocalanus acuspes were derived from a database of a zooplankton monitoring program of the Institute of Food Safety, Animal Health and Environment (BIOR) in Riga, Latvia. Sampling has been conducted seasonally since the 1960s, usually in February, May, August, and October, with a variable number of stations in the Gotland Basin (Fig. S1b, Table S1 in the Supplement). The sampling gear, a Juday net (UNESCO 1979), has a mesh size of $160 \mu \mathrm{m}$, an opening diameter of $0.36 \mathrm{~m}$ and no flow-meter. It is operated vertically and considered to quantitatively catch all larval (i.e. copepodite) stages as well as adult copepods, whereas the first larval stages (i.e. nauplii) may be slightly underestimated. Individual net sampling hauls were carried out to fully cover the water column to a maximum depth of $100 \mathrm{~m}$. Assuming a $100 \%$ filtration efficiency, approximately $10 \mathrm{~m}^{3}$ water were sampled at each sampling. During analysis, abundance of nauplii (N), copepodites I to III (C13), copepodites IV to $\mathrm{V}(\mathrm{C} 45)$, as well as adult females $(\mathrm{F})$ were enumerated. For our analysis, abundance data were averaged to quarterly values for the period 1960 to 2008 .

\section{Hydro-climatic variables and predation pressure}

We used a set of hydro-climatic variables as indicators for bottom-up control on the copepod (Tables S2 \& S3 in the Supplement). The main hydrographic variables affecting Pseudocalanus acuspes are water temperature and salinity (Möllmann et al. 2000). Stage-specific, seasonal temperature time series were computed for specific depth ranges accounting for the ontogenetic vertical distribution of the copepod and related environmental adaptions and preferences (Renz \& Hirche 2006). Seasonal salinity time series were calculated for a deepwater layer (70 to $100 \mathrm{~m}$ depth), where the more salinity-sensitive late copepodite and adult stages reside (Möllmann et al. 2000). Hydrographic data were derived from the International Council for the Exploration of the Sea (ICES; www.ices.dk).

As an indicator for atmospheric variability, we used the Baltic Sea Index (BSI), a local climate mode representing the difference of normalized sea level pressure (SLP) anomalies between Oslo in Norway and Szczecin in Poland. The BSI is correlated to the North Atlantic Oscillation (NAO) index but better relates to oceanographic processes in the Baltic Sea (Lehmann et al. 2002). Annual winter mean values (December to March) were calculated for the BSI, since winter patterns of local and regional wind fields are more pronounced in amplitude and areal coverage and have a strong influence on the hydrographic situation in spring (Dippner et al. 2000), the period most important for the reproductive success of Pseudocalanus acuspes (Renz \& Hirche 2006).

Sprat (Sprattus sprattus) is the major predator of Pseudocalanus acuspes and a suitable indicator of predation pressure (Möllmann et al. 2008). However, stock size estimates from official fish stock assessments for sprat are not available prior to 1974 (ICES 2011). Hence, a predation index (PI) was developed based on stock size estimates for Eastern Baltic cod Gadus morhua, the major piscivore in the Baltic Sea whose stock size is inversely related to that of sprat (Casini et al. 2008, Möllmann et al. 2008). We used spawning stock biomass (SSB) estimates for cod from official stock estimates that date back to 1966 (ICES 2011), and extended the time series back to 1960 using estimates by Eero et al. (2007). The combined time series was inversed to mimic the predation pressure by planktivorous sprat, and scaled to values between 0 and 1 .

Food limitation may be an important bottom-up influence on population dynamics of Pseudocalanus acuspes, but studies on the feeding ecology of the copepod are scarce. Investigations using lipid biomarkers showed a high importance of ciliates in addition to diatoms, dinoflagellates, and cyanobacteria (Peters et al. 2006). No reliable estimates of the food sources for $P$. acuspes were available for our investigation period. Thus, we did not include phytoplankton in our analysis; instead, we considered that bottom-up hydro-climatic variables implicitly represent food availability as well. 


\section{Statistical modeling approach}

We used non-linear regression techniques, i.e. GAM (Hastie \& Tibshirani 1990, Wood 2006), to capture the seasonal population dynamics of Pseudocalanus acuspes and to disentangle the roles of internal life cycle effects (i.e. density effects between successive life stages within and between seasons) relative to external factors (i.e. hydro-climate and predation). The following model was used for the seasonal abundance of each life-history stage:

$$
X_{S Y}=\alpha+\Sigma_{i} f_{i}\left(\mathbf{D}^{i}\right)+\Sigma_{j} g_{j}\left(\mathbf{I}_{Y}^{j}\right)+\varepsilon_{S Y}
$$

where $X_{S Y}$ is the natural logarithm $(\ln (X+1))$ of the abundance of a particular life stage group (i.e. N, C13, C45, and F) of $P$. acuspes during a particular season $s$ in year $y$ (Table $\mathbf{S} 2$ in the Supplement). $\mathbf{D}^{i}$ represents a vector of density effects, i.e. $\ln (X+1)$ transformed population abundances of different stage groups in the same or previous season of year $y$ or $y-1$ (Table S3 in the Supplement). Hydro-climatic and predation variables of the same year $y$ (and in the case of temperature and salinity, also the same season) are summarized in the row vector $\mathbf{I}_{y}^{j}$. The superscripts $i$ and $j$ identify the single components of both vectors. $\alpha$ is the intercept, and $\varepsilon_{s Y}$ is a random noise term assumed to be normally distributed with zero mean and finite variance. $f_{i}$ and $g_{j}$ are thin-plate regression spline functions describing the effect of internal and external processes respectively. The $\ln (X+1)$ transformation was applied to all seasonal stage abundance data of $P$. acuspes to reduce intrinsic mean-variance relationships. It is important to note that we could not test for density dependence as a regulatory mechanism for population growth, as we did not model the growth or survival rate. Modeling log-transformed current population size as a function of log-transformed previous population size is often sensitive to observation uncertainty (Knape \& de Valpine 2012), which can increase type I error rates (Shenk et al. 1998) and lead to bias estimates of overor under-compensatory dynamics (Benson 1973). We hence will term the dependence between subsequent stage abundances simply as density effect.

Stage group abundances were modeled for seasons, in which they dominated the total abundance or played a major ecological role (e.g. reproducing females in spring). Due to the seasonal resolution of the sampling and the slow development times of Pseudocalanus acuspes (Renz \& Hirche 2006), we used abundances of the same or preceding stage or initially reproducing females from season $s$ and $s-1$ as predictors. The PI was only used as predictor for
C45 and F known to be consumed by sprat (Möllmann et al. 2004). Model selection was conducted applying a stepwise backward approach starting with the full model (Table S3 in the Supplement). The least significant variables $(p>0.05)$ were individually removed until the generalized cross-validation criterion $(\mathrm{GCV}$, a proxy for the out-of-sample predictive performance) of the model was minimized (Wood 2000). To avoid over-fitting, we let the effective degrees of freedom (edf) be restricted to a maximum of 4 . Final models including parameters with smoothers of one degree of freedom (linear relationship) were refitted in which these variables were added as linear terms. The underlying statistical assumptions were then tested through graphical residual analyses, which showed no evidence of nonlinearity, heterogeneity, or serial autocorrelation (Figs. S2 to S9 in the Supplement; for data handling and outliers, see text 'Data handling and outliers' in the Supplement).

\section{Non-additive interactions}

After identifying the main population dynamics and drivers of Pseudocalanus acuspes, we tested for changes between bottom-up and top-down control for F and C45 (the life stages affected by predators). We applied a non-additive threshold formulation (TGAM) using the PI as a threshold variable and applied it to density and hydro-climatic variables that were significant in the initial GAM analyses (Fig. S3 in the Supplement) as well as to the PI itself. TGAMs are useful if changes in the response to external driving variables are discrete (see Ciannelli et al. 2004 for a detailed description of TGAMs). They are composed of 2 additive formulations in which the relationship between modeled stage group abundance and each explanatory variable can have different shapes in years above and below a level $r$ of the threshold variable:

$$
\begin{gathered}
X_{S Y}=\alpha+\Sigma_{i} f_{1, i}\left(\mathbf{D}^{i}\right)+\Sigma_{j} g_{1, j}\left(\mathbf{I}_{Y}^{j}\right)+\varepsilon_{S Y} \text { if PI } \leq r \\
X_{S Y}=\alpha+\Sigma_{i} f_{2, i}\left(\mathbf{D}^{i}\right)+\Sigma_{j} g_{2, j}\left(\mathbf{I}_{Y}^{j}\right)+\varepsilon_{S Y} \text { otherwise }
\end{gathered}
$$

$r$ is here the predation threshold across which the functions of the density-dependent and -independent variables switch from $f_{1, i}$ to $f_{2, i}$ and $g_{1, j}$ to $g_{2, j}$ respectively. The threshold is estimated from the data and chosen by minimizing the GCV score over an interval defined by the 10th and 90th percentiles of the PI (Ciannelli et al. 2004). The edf were here restricted to a maximum of 3 to avoid over-smoothing and high model complexities. In order to determine the best modeling approach and compare GAM and 
TGAM models, we used as the criterion the 'genuine' cross-validatory squared prediction error (gCV), which has the advantage of accounting for the parameters defining the threshold (Ciannelli et al. 2004).

All analyses were performed using the package 'mgcv' (with version R2.10) (Wood 2006) and the 'tgam' library (with version R2.5) (created by K.-S. Chan for version R2.5 and based on the mgcv library) within the $\mathrm{R}$ statistical and programming environment (R Development Core Team 2009).

\section{RESULTS}

\section{Pseudocalanus acuspes population dynamics}

The life cycle of Pseudocalanus acuspes is characterized by a reproduction period in spring when overall abundance peaks, and F, N, and C13 dominate the population (Fig. 1a). During summer and autumn, $\mathrm{N}$ develop through $\mathrm{C} 13$ to $\mathrm{C} 45$. The latter eventually constitute most of the overwintering stock together with a small population of developing adult males (M) and F. Long-term trends of the seasonally dominant stage groups displayed a major peak during the 1970s and early 1980s, observed a few years earlier for $\mathrm{N}$ and $\mathrm{C} 13$ (Fig. 1b-e). C45 in winter and F and $\mathrm{N}$ in spring showed a second but minor peak during the last decade, while C13 in summer and autumn increased in abundance.

\section{Internal density and external environmental effects}

Final GAM formulations as a function of preceding stage-specific abundances (i.e. density effects) as well as external biotic and abiotic drivers (i.e. predation and hydro-climate) explained variances (adjusted $\mathrm{R}^{2}$ ) of 35 to $80 \%$ (Table 1 ). The residuals showed no serial auto-correlation (Figs. S2b to S9b in the Supplement), indicating that the set of final models captured most of the population's variability. Across most of the stages, positive linear density effects were observed, as indicated by an edf close to 1 (Fig. 2).
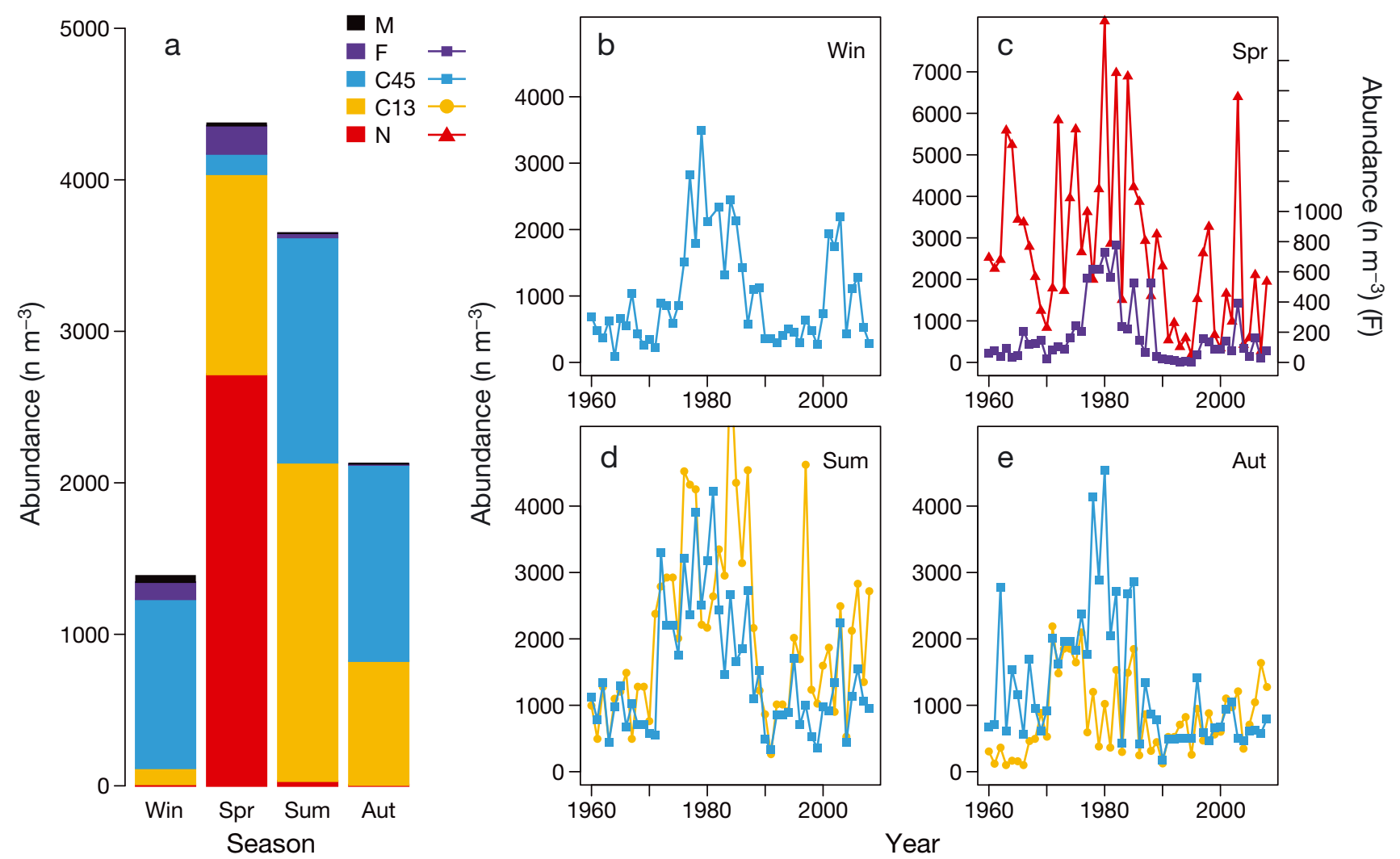

Fig. 1. Seasonal stage distribution and inter-annual stage dynamics of Pseudocalanus acuspes with (a) the distribution of absolute stage abundances in each season, identifying spring as the main reproductive season with a peak of females (F) and nauplii (N), and the successive accumulation of late copepodite (C45) stages thereafter, and (b-e) long-term dynamics of the major stage groups in each season (Win $=$ winter, $\mathrm{Spr}=$ spring, $\mathrm{Sum}=$ summer, Aut $=$ autumn). C13= early copepodites, 
Table 1. Summary results of the final generalized additive models (GAMs) and the alternative threshold formulations (TGAMs) used to describe Pseudocalanus acuspes. stage abundances in each season. Coefficients are given for linear terms in the GAM. Superscripted plus sign or asterisks indicate the significance of each predictor $\left({ }^{+} p<0.1,{ }^{*} p<0.05,{ }^{* *} p<0.01,{ }^{* * *} p<0.001\right)$. Adjusted $\mathrm{R}^{2}$ are given for all models, but the genuine cross-validation ( $\mathrm{gCV}$ ) scores only for competing GAMs and TGAMs. Models with a less optimal performance, i.e. with a higher gCV score, are marked in grey letters. For abbreviations of variables, see Table S2 in the Supplement as well as Eqs. (1) \& (2) in the main paper

\begin{tabular}{|c|c|c|c|c|c|}
\hline Season & $\begin{array}{l}\text { Response } \\
\text { variable }\end{array}$ & $\begin{array}{l}\text { Model } \\
\text { type }\end{array}$ & Formulation & $\begin{array}{c}\text { Adj. } \\
\mathrm{R}^{2}(\%)\end{array}$ & $\mathrm{gCV}$ \\
\hline Winter & $\mathrm{C} 45_{\text {win }}$ & $\begin{array}{l}\text { GAM } \\
\text { TGAM }\end{array}$ & 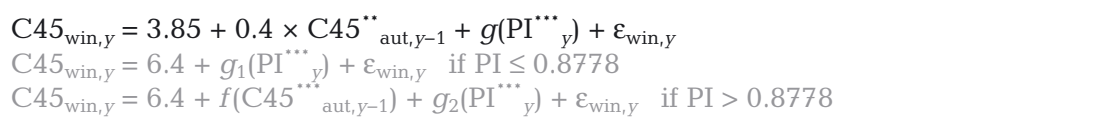 & $\begin{array}{l}57.3 \\
69.1\end{array}$ & $\begin{array}{l}0.614 \\
0.876\end{array}$ \\
\hline Spring & $\begin{array}{l}\mathrm{N}_{\text {spr }} \\
\mathrm{C} 13_{\text {spr }} \\
\mathrm{F}_{\text {spr }}\end{array}$ & $\begin{array}{l}\text { GAM } \\
\text { GAM } \\
\text { GAM } \\
\text { TGAM }\end{array}$ & 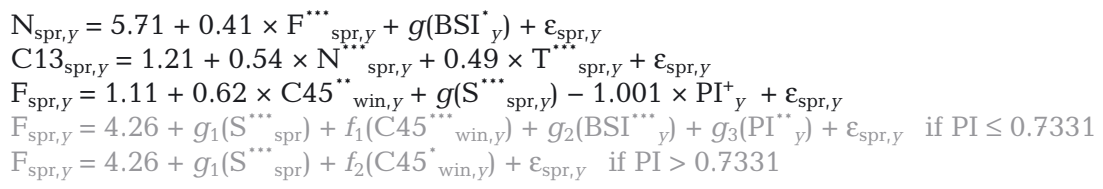 & $\begin{array}{l}52.0 \\
35.0 \\
65.6 \\
79.3\end{array}$ & $\begin{array}{c}- \\
- \\
0.926 \\
1.489\end{array}$ \\
\hline Summer & $\begin{array}{l}\text { C13 }{ }_{\text {sum }} \\
\text { C45 sum }\end{array}$ & $\begin{array}{l}\text { GAM } \\
\text { GAM } \\
\text { TGAM }\end{array}$ & 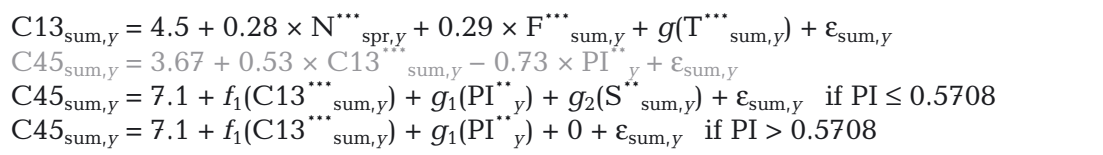 & $\begin{array}{l}60.4 \\
60.8 \\
66.1\end{array}$ & $\begin{array}{l}- \\
0.421 \\
0.395\end{array}$ \\
\hline Autumn & $\begin{array}{l}\mathrm{C} 13_{\text {aut }} \\
\mathrm{C} 45_{\text {aut }}\end{array}$ & $\begin{array}{l}\text { GAM } \\
\text { GAM } \\
\text { TGAM }\end{array}$ & 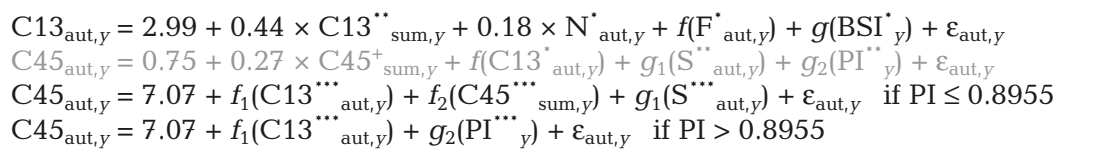 & $\begin{array}{l}47.4 \\
58.7 \\
72.9\end{array}$ & $\begin{array}{l}- \\
0.572 \\
0.463\end{array}$ \\
\hline
\end{tabular}

For C13 in autumn, the partial effects of $\mathrm{N}$ and $\mathrm{F}$ autumn abundances in the final model were slightly zero-inflated. Both $\mathrm{N}$ and $\mathrm{F}$ are scarce during the autumn season. Including these in the $\mathrm{C} 13_{\text {aut }}$ model decreased the GCV value, increased the explained variance from 32 to $57 \%$, and also improved residuals, and were, hence, retained in the model.

Impacts of the hydro-climatic variables were stageand season-specific and highly non-linear. We observed significant temperature effects on C13 in spring and summer. While the relationship was dome-shaped in summer (Fig. 2e), the effect on spring C13 was almost linear (Fig. 2c). Complex nonlinear, albeit weak, relationships with the BSI were derived for $\mathrm{N}$ in spring and $\mathrm{C} 13$ in autumn. C45 and $\mathrm{F}$ were, in contrast to the younger stages, mainly affected by salinity. We found a strong positive and linear effect of salinity on C45 in autumn and a positive, but saturating non-linear effect for $\mathrm{F}$ in spring (Fig. 2d,h). Predation had a negative linear effect on older stages, although not significant for spring $F$ (Fig. 2d,f,h).

\section{Non-additive interactions}

We found the threshold formulations that distinguish between high and low predation regimes to be preferred to their additive equivalents for C45 in summer and autumn (Fig. 3, Table 1). Significant models indicate a stronger bottom-up regulation through salinity and internal density effects (in autumn) during the low predation regime (Fig. 3a,b). Above the predation threshold, the bottom-up effects diminished, and in autumn, the negative predation effect became significant. In summer, predation was a significant predictor for C45 irrespective of the predation regime, and the predation threshold was lower $(\mathrm{PI}=0.571$ ) compared to autumn $(\mathrm{PI}=0.896)$.

\section{DISCUSSION}

\section{Pseudocalanus acuspes life cycle}

Our integrative statistical analysis demonstrates the dominance of internal density effects in the life cycle of Pseudocalanus acuspes (Fig. 4a). Density effects, i.e. the dependence of a life stage on the abundance of the previous stage or the same stage in the previous season, explain most of the variability in population size of the different $P$. acuspes life stages (Fig. 4a). Statistical relationships were mostly linear in the log-log space, as has been shown in life stage models of fish and zooplankton species (Dingsør et al. 2007, Persson et al. 2012). 

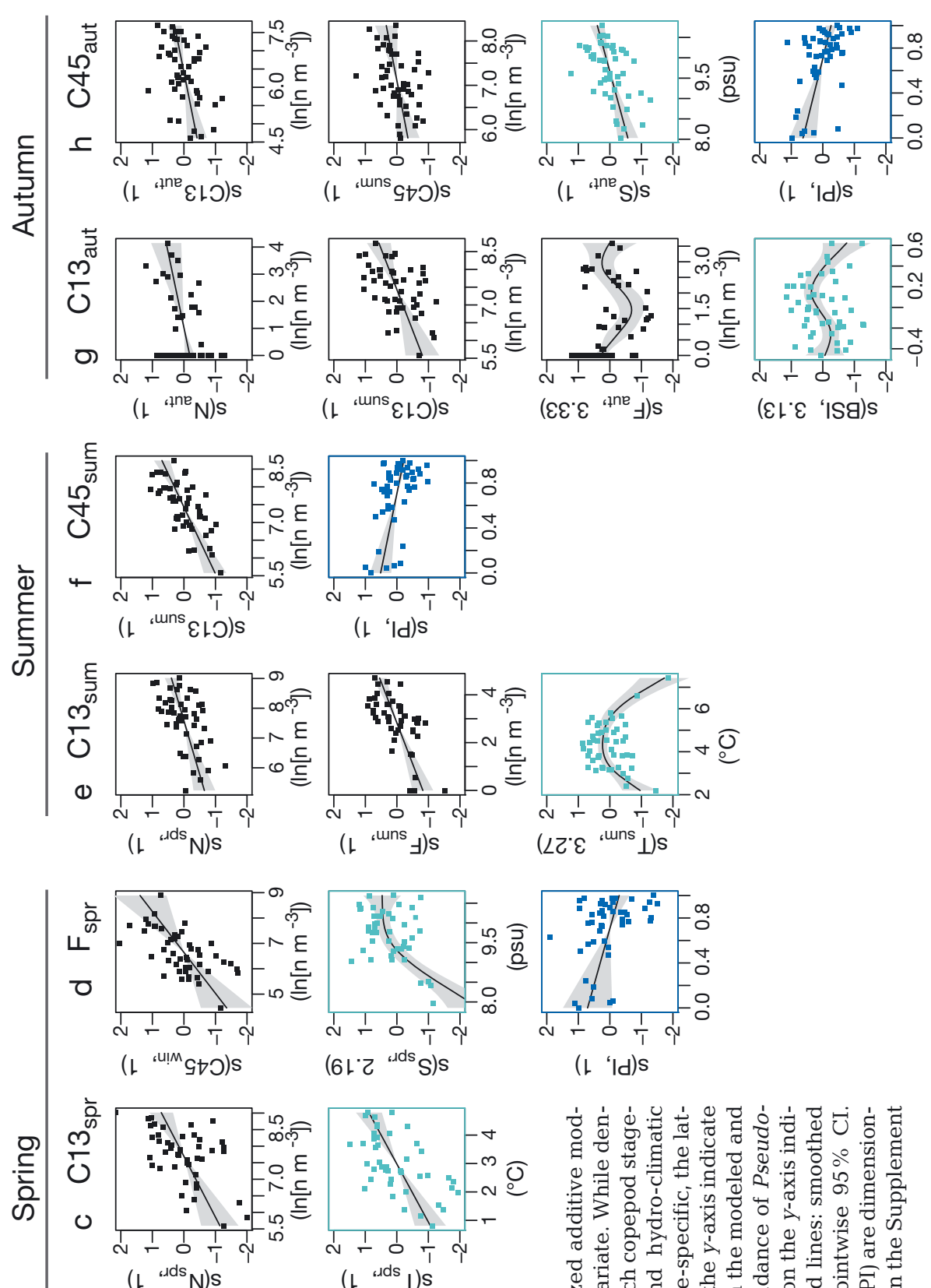

$\left(6 L^{\circ} \mathrm{d}\right.$ 'ds)s

( 1 'Id)s
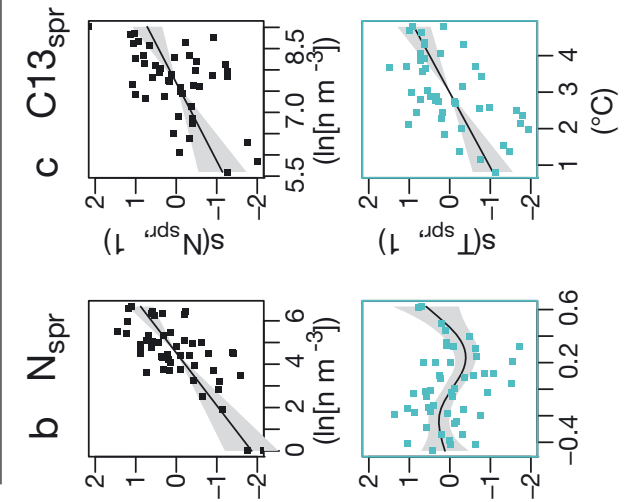

$(1$ ،dds $\lrcorner) s$

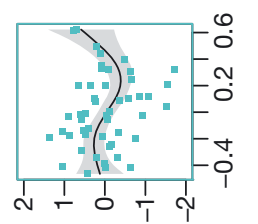

(90. 'ISg)s

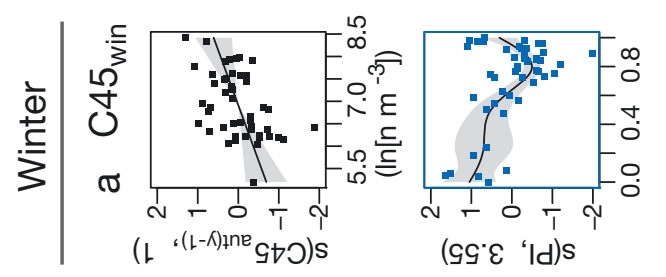

A general pattern of stage succession emerged from our statistical analysis explaining the main life cycle of our model species. The abundance of reproducing $F$ in spring is determined by the C45 population that has survived the winter. This dependence of the new generation on the overwintering stock has been shown for Pseudocalanus sp. in Dabob Bay (Ohman 1985) and also the Baltic Sea using a seasonally resolved 2 yr data set (Peters et al. 2006). Subsequent offspring (N) production in spring, generally a critical phase in copepod dynamics, depends almost exclusively on the developing $\mathrm{F}$ abundance. The magnitude of offspring produced in spring determines the accumulation of first early copepodites (C13) and then $\mathrm{C} 45$ in summer and autumn. Eventually the life cycle is closed by the developing overwintering $\mathrm{C} 45$ population.

\section{Effects of hydro-climatic drivers}

In addition to the prevailing internal density effects, external factors influence the dynamics of Pseudocalanus acuspes. The effects of abiotic conditions were clearly specific for individual life stages (Fig. 4b), reflecting the variations in their realized niches (Helaouët \& Beaugrand 2009). Younger stages of $P$. acuspes (i.e. $\mathrm{N}$ and $\mathrm{C} 13$ ) that reside in the upper water column responded only to local thermal conditions, indicated by the BSI and water temperature. Large-scale, lowfrequency climatic indices such as the BSI have proven to be suitable predictors for long-term changes in the ecology of marine zooplankton (e.g. Fromentin \& 

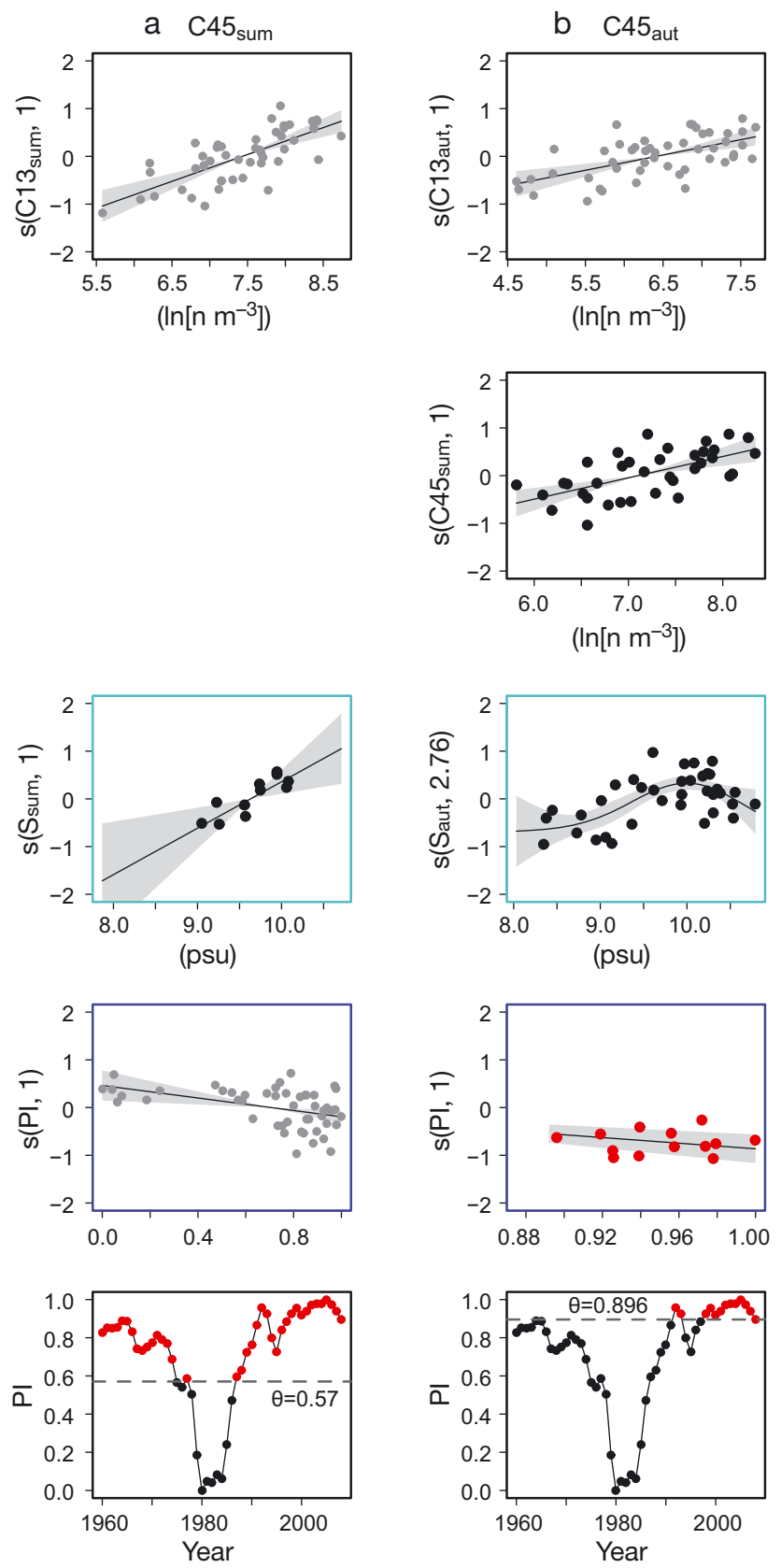

Fig. 3. Threshold generalized additive models (TGAMs) that outperformed corresponding generalized additive models (GAMs). Partial plots are presented as described in Fig. 2 for late copepodite stages (C45) of Pseudocalanus acuspes in (a) summer and (b) autumn, including the threshold estimation $(\theta)$. Grey dots represent residuals for the whole predation regime (i.e. additive effect), black and red dots represent residuals of low and high regimes, respectively (i.e. non-additive effect). Effects of early copepodites (C13) density and predation index (PI) in summer are independent of the predation regime, while bottom-up effects of C45 density and salinity (S) are only significant under a low predation regime. Predation itself always has a negative effect on $\mathrm{C} 45$ summer abundances, but on autumn abundances only at high PI levels. The bottom panels display trajectories of the PI with high and low regimes in red and black, respectively
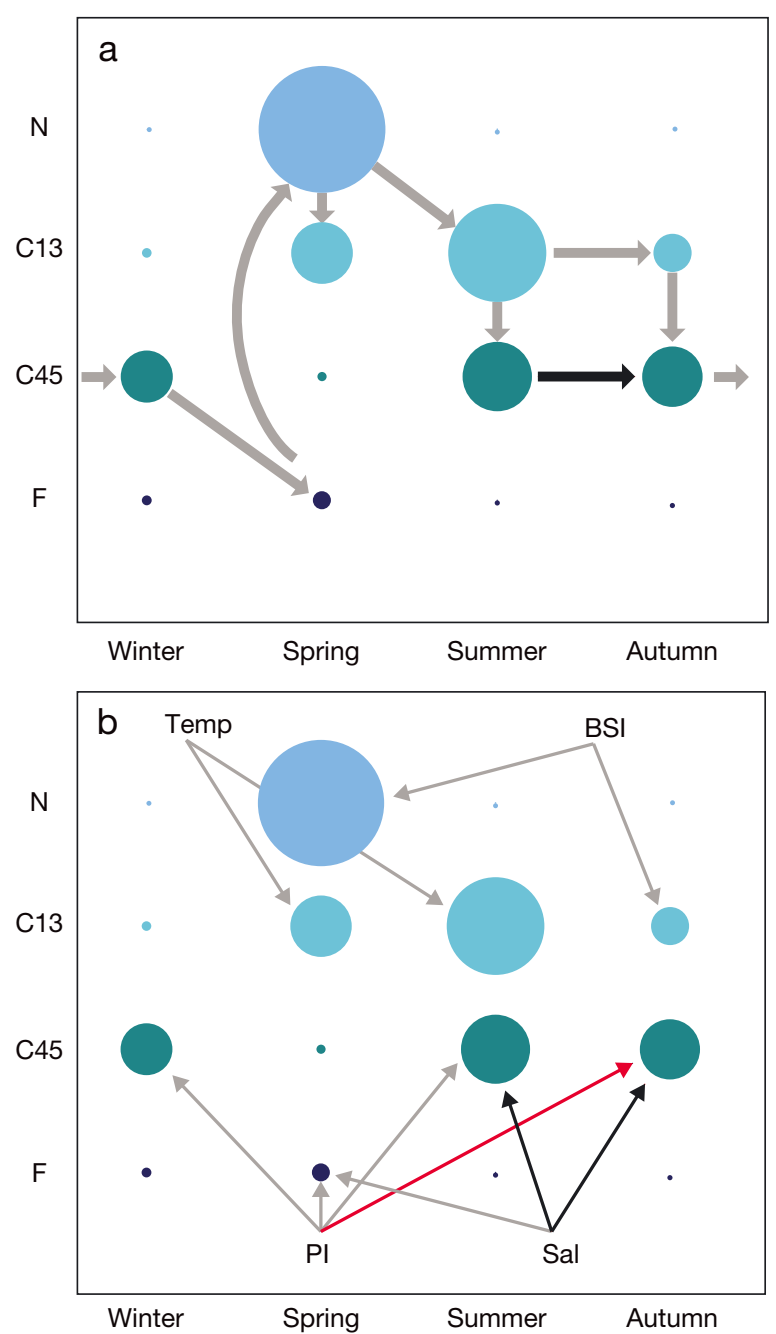

Fig. 4. Conceptual diagram of the annual life cycle of Pseudocalanus acuspes showing (a) density effects and (b) external hydro-climatic and predation effects on the different stage groups that show an ontogenetic vertical distribution. Sizes of the solid circles of each stage group in all 4 seasons (i.e. yearly quarter) are approximate representations of the proportional contributions of each stage group to the total seasonal abundances. Effects independent of the level of predation are presented by grey arrows. Effects that are only significant under a low or high predation pressure are indicated by black and red arrows, respectively. Weak significant density effects $(\mathrm{p}<0.01)$ are not presented here. $\mathrm{N}=$ nauplii, C13 = early copepodites, C45 = late copepodites, F = adult females (different stages represented by different shades of blue), Temp = temperature, BSI = Baltic Sea Index, $\mathrm{PI}=$ predation index, $\mathrm{Sal}=$ salinity

Planque 1996, Beaugrand 2003). We found significant although weak effects of the BSI on $\mathrm{N}$ in spring and $\mathrm{C} 13$ in autumn. A stronger effect was prevalent for temperature on $\mathrm{C} 13$ in spring and summer. A non-linear relationship suggests an optimum range of 4 to $5^{\circ} \mathrm{C}$ for the realized thermal niche, which is 
higher than for $P$. acuspes in the Chukchi Sea, which prefers temperatures $<3^{\circ} \mathrm{C}$ (Hopcroft \& Kosobokova 2010). Previous long-term studies in the Baltic Sea only found weak negative (Möllmann et al. 2000) or no relationships between $P$. acuspes biomass and temperature (Dippner et al. 2000, Möllmann et al. 2000). In those studies, however, no stage-specific responses were investigated, and hence any temperature response of younger copepodites was likely superimposed by older stages. Furthermore, earlier studies used shorter time periods and only linear regression techniques and hence failed to capture a non-linear relationship.

Temperature is known to affect growth rates, development times, and molting rates of early copepodite stages (Vidal 1980b, Hirst \& Bunker 2003, Liu \& Hopcroft 2008). With increasing body size, and hence age, growth rate becomes less temperaturedependent (Vidal 1980a, Dzierzbicka-Glowacka 2004). Younger copepodite stages have therefore optimized their growth at higher temperatures, even if food supply is low, whereas under similar food conditions, older stages experience higher growth at lower temperatures. This might explain why we did not find significant temperature effects for older stages. Unfortunately, we could not test the direct effect of food availability on Pseudocalanus acuspes, since we lack adequate phytoplankton time series. Recent studies show for the Baltic Sea and adjacent seas that major shifts in phytoplankton composition can be induced by changes in temperature and wind conditions affecting the vertical mixing (Wasmund \& Uhlig 2003, Wasmund et al. 2011, Hinder et al. 2012). The observed decrease of diatoms and increase of dinoflagellates in the Gotland Basin in recent years (Wasmund \& Uhlig 2003) could have had implications for the food quality important for growth and reproduction (Gulati \& Demott 1997). While older stages of $P$. acupses are known to feed mainly on heterotrophic organisms like small flagellates and ciliates as well as detritus (Peters et al. 2006), younger stages near the surface could more likely be influenced by poor quality of phytoplankton species.

The dynamics of C45 and F that live in deeper water layers are mainly determined by deepwater salinity. Pseudocalanus acuspes in the Baltic Sea is generally perceived as being more driven by salinity than by temperature (Dippner et al. 2000, Möllmann et al. 2000) because the low-saline, brackish water offers only suboptimal reproductive conditions for this species of marine origin (Renz \& Hirche 2006). In our analysis, salinity had the strongest and most significant impact on female abundance in spring. Dur- ing this main reproduction season, females inhabit the deeper and more saline parts of the water column, where they can avoid osmotic stress and hence save energy for their gonad development and reproduction (Möllmann et al. 2008). Despite the generally observed positive influence of higher salinity (e.g. Ojaveer et al. 1998, Möllmann et al. 2000, Renz \& Hirche 2006), we found non-linear relationships and the effect to be strongest at lower salinities. Above salinity 10 , a salinity increase did not lead to significantly higher abundances, indicating a critical salinity threshold below which osmoregulation might boost energy requirements to unsustainably high levels, affecting not only reproduction but also respiration and feeding rates (Mauchline 1998), slowing down growth and molting rates (Renz et al. 2007), and changing protein synthesis (Kimmel \& Bradley 2001). In addition, extremely low deepwater salinities due to the lack of major saltwater intrusions are often associated with strong declines in oxygen concentrations. This decline can cause a vertical displacement of the hypoxia horizon and consequently a reduction in suitable habitat space (Doney et al. 2012), which increases competition.

\section{Predation effects and non-additive interactions with hydro-climatic drivers}

In addition to external abiotic factors, we investigated predation as a biotic control factor for Pseudocalanus acuspes. The predation effect is limited to older stages (C45 and F) and is generally linear (Casini et al. 2008, Möllmann et al. 2008, Llope et al. 2011). We observed a few years with high abundances of C45 occurring concurrently with high predation pressures, which is ecologically difficult to explain, and may indicate observation error related to our measure of predation. In the absence of planktivorous fish population sizes for the entire study period, we used an indirect measure of predation, i.e. the inverse of the cod population size. This procedure assumes a stable, inverse cod-sprat relationship, which may not be valid for the longer period investigated here. Furthermore, the other large planktivorous fish stock of the Baltic (i.e. herring) is disregarded in our analysis, since earlier studies were not able to find a significant negative relationship with zooplankton (Casini et al. 2008, Möllmann et al. 2008). In spite of the uncertainty in our PI, the results of our statistical modeling exercise give us confidence in the approach. We found significant negative relationships with the PI for C45 and F, which is in accordance with 
size-specific foraging of copepods. Also, our study supports results from earlier studies that show significant top-down control of $P$. acuspes by sprat based on significantly shorter time series (Casini et al. 2008).

Relationships between bottom-up and top-down control variables are often not stable in marine ecosystems (Ciannelli et al. 2004, Frank et al. 2007, Casini et al. 2009). Here, we tested for non-additive effects of explanatory variables and applied a threshold formulation for GAMs to our data. We demonstrated that density effects as well as effects of hydroclimatic variables can depend on the level of predation pressure. In our case of Pseudocalanus acuspes, non-additive interactions eventually determined the size of the overwintering stock, an important determinant of long-term population dynamics. Here, the survival of $\mathrm{C} 45$ between summer and autumn, and the effect of salinity on C45, are only significant when there is a low predator stock. Predation, on the other hand, is only significant during a large planktivore population. Stige et al. (2009) made a similar observation for the Barents Sea, and found a positive association between spring and summer zooplankton biomass only under a low feeding regime of the predator capelin. The decoupling of zooplankton dynamics from climate/hydrography by high predator abundances has also been observed for the Black and Barents seas (Stige et al. 2009, Llope et al. 2011) as well as for the Baltic Sea for a shorter summer biomass time series (Casini et al. 2009). In the Baltic, sprat individuals usually leave the deeper Baltic basins, where $P$. acuspes resides, during summer and autumn and move into shallower water layers or migrate to coastal areas (Stepputtis 2006), lowering hereby the predation pressure. Consequently, bottom-up control dominates mainly the summer and autumn C45 populations. However, in years where the sprat stock reaches a certain size, more sprat individuals are likely to remain in the deeper part of the basins to reduce intraspecific competition (Ciannelli et al. 2012), which ultimately induces a stronger top-down regulation. A recent study on Pseudocalanus sp. in the Gulf of Maine indicates a stronger sensitivity to top-down forcing than phytoplankton dynamics for this species (Ji et al. 2013), although top-down processes could not explain alone the observed zooplankton variability and are suggested to interact non-linearly with bottom-up processes. With regard to this debate on whether zooplankton is bottom-up or top-down regulated, our results add to the increasing evidence that both regulatory processes can alternate and act simultaneously (Frank et al. 2007, Casini et al. 2009, Stige et al. 2009).

\section{CONCLUSIONS}

Our novel statistical analysis of the complex life cycle of Pseudocalanus acuspes revealed that changes in hydro-climate (i.e. temperature and salinity) as well top-down predation pressure explain the historical long-term dynamics of this important species in the Baltic Sea food web. The peak abundance in the late 1970 s to early 1980 s was caused by the synergistic effects of high salinity, intermediate temperatures, and a lowering in predation pressure, while the decrease during the late 1980s to early 1990s was due to reversed hydro-climatic conditions. A high predation pressure towards the end of the time series keeps the population in a low state, representing partly a non-additive effect overruling increased salinity levels that support offspring production.

We show that external bottom-up hydro-climatic effects and top-down predation pressure are strongly stage-specific and propagate through the life cycle. Our study hence demonstrates the complex and nonstationary interplay between internal and external factors regulating long-term animal population dynamics. Our results suggest that population models of key ecosystem species for projecting future effects of climate change and anthropogenic impact need to account for this life-history complexity.

Acknowledgements. We thank colleagues from the Department of Fish Resources Research, Institute of Food Safety, Animal Health and Environment (BIOR) in Riga, Latvia, for maintaining this extensive long-term monitoring program. The time series on the BSI was kindly provided by HansHarald Hinrichsen (Helmholtz Centre for Ocean Research, Kiel, Germany). This study was supported by the BONUS project 'Assessment and Modelling Baltic Ecosystem Response (AMBER)'. M.L. acknowledges partial support from a Marie Curie European Reintegration Grant (FP7-People-2009-RG). Financial support was received from Stockholm University's strategic marine environmental research funds through the Baltic Ecosystem Adaptive Management Program (BEAM).

\section{LITERATURE CITED}

Arcese P, Smith JNM (1988) Effects of population-density and supplemental food on reproduction in song sparrows. J Anim Ecol 57:119-136

Banse K (1995) Zooplankton: pivotal role in the control of ocean production. ICES J Mar Sci 52:265-277

Baum JK, Worm B (2009) Cascading top-down effects of changing oceanic predator abundances. J Anim Ecol 78: 699-714

Beaugrand G (2003) Long-term changes in copepod abundance and diversity in the north-east Atlantic in relation to fluctuations in the hydroclimatic environment. Fish Oceanogr 12:270-283 
Benson JF (1973) Some problems of testing for densitydependence in animal populations. Oecologia 13: 183-190

Benton TG, Plaistow SJ, Coulson TN (2006) Complex population dynamics and complex causation: devils, details and demography. Proc R Soc B Biol Sci 273:1173-1181

Bjørnstad ON, Grenfell BT (2001) Noisy clockwork: time series analysis of population fluctuations in animals. Science 293:638-643

Boggs CL, Inouye DW (2012) A single climate driver has direct and indirect effects on insect population dynamics. Ecol Lett 15:502-508

> Brooks JL, Dodson SI (1965) Predation, body size, and competition of plankton: the effect of a marine planktivore on lake plankton illustrates theory of size, competition, and predation. Science 150:28-35

Burrows MT, Schoeman DS, Buckley LB, Moore P and others (2011) The pace of shifting climate in marine and terrestrial ecosystems. Science 334:652-655

> Cardinale BJ, Duffy JE, Gonzalez A, Hooper DU and others (2012) Biodiversity loss and its impact on humanity. Nature 486:59-67

> Casini M, Lövgren J, Hjelm J, Cardinale M, Molinero JC, Kornilovs G (2008) Multi-level trophic cascades in a heavily exploited open marine ecosystem. Proc R Soc B Biol Sci 275:1793-1801

> Casini M, Hjelm J, Molinero JC, Lövgren J and others (2009) Trophic cascades promote threshold-like shifts in pelagic marine ecosystems. Proc Natl Acad Sci USA 106:197-202

Ciannelli L, Chan KS, Bailey KM, Stenseth NC (2004) Nonadditive effects of the environment on the survival of a large marine fish population. Ecology 85:3418-3427

> Ciannelli L, Bartolino V, Chan KS (2012) Non-additive and non-stationary properties in the spatial distribution of a large marine fish population. Proc R Soc B Biol Sci 279: 3635-3642

> Corkett CJ, McLaren IA (1978) The biology of Pseudocalanus. Adv Mar Biol 15:1-231

Daskalov GM, Grishin AN, Rodionov S, Mihneva V (2007) Trophic cascades triggered by overfishing reveal possible mechanisms of ecosystem regime shifts. Proc Natl Acad Sci USA 104:10518-10523

> Dingsør GE, Ciannelli L, Chan KS, Ottersen G, Stenseth NC (2007) Density dependence and density independence during the early life stages of four marine fish stocks. Ecology 88:625-634

> Dippner JW, Kornilovs G, Sidrevics L (2000) Long-term variability of mesozooplankton in the Central Baltic Sea. J Mar Syst 25:23-31

> Doney SC, Ruckelshaus M, Duffy JE, Barry JP and others (2012) Climate change impacts on marine ecosystems. Annu Rev Mar Sci 4:11-37

> Dzierzbicka-Glowacka L (2004) Growth and development of copepodite stages of Pseudocalanus spp. J Plankton Res 26:49-60

Eero M, Köster FW, Plikshs M, Thurow F (2007) Eastern Baltic cod (Gadus morhua callarias) stock dynamics: extending the analytical assessment back to the mid1940s. ICES J Mar Sci 64:1257-1271

- Frank KT, Petrie B, Shackell NL, Choi JS (2006) Reconciling differences in trophic control in mid-latitude marine ecosystems. Ecol Lett 9:1096-1105

Frank KT, Petrie B, Shackell NL (2007) The ups and downs of trophic control in continental shelf ecosystems. Trends Ecol Evol 22:236-242
Fromentin JM, Planque B (1996) Calanus and environment in the eastern North Atlantic. II. Influence of the North Atlantic Oscillation on C. finmarchicus and C. helgolandicus. Mar Ecol Prog Ser 134:111-118

Gulati R, Demott W (1997) The role of food quality for zooplankton: remarks on the state-of-the-art, perspectives and priorities. Freshw Biol 38:753-768

Hastie TJ, Tibshirani RJ (1990) Generalized additive models, Vol 43. Chapman \& Hall/CRC, Boca Raton. FL

Hays GC, Richardson AJ, Robinson C (2005) Climate change and marine plankton. Trends Ecol Evol 20:337-344

> Helaouët P, Beaugrand G (2009) Physiology, ecological niches and species distribution. Ecosystems 12:1235-1245

Hinder SL, Hays GC, Edwards M, Roberts EC, Walne AW, Gravenor MB (2012) Changes in marine dinoflagellate and diatom abundance under climate change. Nat Clim Change 2:271-275

Hirst AG, Bunker AJ (2003) Growth of marine planktonic copepods: global rates and patterns in relation to chlorophyll $a$, temperature, and body weight. Limnol Oceanogr 48:1988-2010

> Hopcroft RR, Kosobokova KN (2010) Distribution and egg production of Pseudocalanus species in the Chukchi Sea. Deep-Sea Res II 57:49-56

> Hunt GL, McKinnell S (2006) Interplay between top-down, bottom-up, and wasp-waist control in marine ecosystems. Prog Oceanogr 68:115-124

ICES (2011) Report of the Baltic Fisheries Assessment Working Group (WGBFAS), 12-19 April 2011, ICES CM 2011/ ACOM:10. ICES, Copenhagen

Ji R, Stegert C, Davis CS (2013) Sensitivity of copepod populations to bottom-up and top-down forcing: a modeling study in the Gulf of Maine region. J Plankton Res 35: 66-79

Kimmel DG, Bradley BP (2001) Specific protein responses in the calanoid copepod Eurytemora affinis (Poppe, 1880) to salinity and temperature variation. J Exp Mar Biol Ecol 266:135-149

Kingsolver JG, Woods HA, Buckley LB, Potter KA, MacLean HJ, Higgins JK (2011) Complex life cycles and the responses of insects to climate change. Integr Comp Biol 51:719-732

- Knape J, de Valpine P (2012) Are patterns of density dependence in the Global Population Dynamics Database driven by uncertainty about population abundance? Ecol Lett 15:17-23

Lehmann A, Krauss W, Hinrichsen HH (2002) Effects of remote and local atmospheric forcing on circulation and upwelling in the Baltic Sea. Tellus A Dyn Meteorol Oceanogr 54:299-316

Litzow MA, Ciannelli L (2007) Oscillating trophic control induces community reorganization in a marine ecosystem. Ecol Lett 10:1124-1134

Liu H, Hopcroft RR (2008) Growth and development of Pseudocalanus spp. in the northern Gulf of Alaska. J Plankton Res 30:923-935

Llope M, Daskalov GM, Rouyer TA, Mihneva V, Chan KS, Grishin AN, Stenseth NC (2011) Overfishing of top predators eroded the resilience of the Black Sea system regardless of the climate and anthropogenic conditions. Glob Change Biol 17:1251-1265

Mauchline J (1998) The biology of calanoid copepods. Academic Press, San Diego, CA

Miller CB (2005) Biological oceanography. Blackwell Publishing, Malden, MA 
Möllmann C, Diekmann R (2012) Marine ecosystem regime shifts induced by climate and overfishing: a review for the Northern hemisphere. Adv Ecol Res 47:303-347

Möllmann C, Kornilovs G, Sidrevics L (2000) Long-term dynamics of main mesozooplankton species in the central Baltic Sea. J Plankton Res 22:2015-2038

- Möllmann C, Kornilovs G, Fetter M, Köster FW, Hinrichsen HH (2003) The marine copepod, Pseudocalanus elongatus, as a mediator between climate variability and fisheries in the Central Baltic Sea. Fish Oceanogr 12:360-368

Möllmann C, Kornilovs G, Fetters M, Köster FW (2004) Feeding ecology of central Baltic Sea herring and sprat. J Fish Biol 65:1563-1581

Möllmann C, Müller-Karulis B, Kornilovs G, St. John MA (2008) Effects of climate and overfishing on zooplankton dynamics and ecosystem structure: regime shifts, trophic cascade, and feedback loops in a simple ecosystem. ICES J Mar Sci 65:302-310

Möllmann C, Diekmann R, Müller-Karulis B, Kornilovs G, Plikshs M, Axe P (2009) Reorganization of a large marine ecosystem due to atmospheric and anthropogenic pressure: a discontinuous regime shift in the Central Baltic Sea. Glob Change Biol 15:1377-1393

Ohman MD (1985) Resource-satiated population growth of the copepod Pseudocalanus sp. Arch Hydrobiol Beih Ergebn Limnol 21:15-32

Ojaveer E, Lumberg A, Ojaveer H (1998) Highlights of zooplankton dynamics in Estonian waters (Baltic Sea). ICES J Mar Sci 55:748-755

> Persson J, Stige LC, Stenseth NC, Usov N, Martynova D (2012) Scale-dependent effects of climate on two copepod species, Calanus glacialis and Pseudocalanus minutus, in an Arctic-boreal sea. Mar Ecol Prog Ser 468:71-83

Peters J, Renz J, Beusekom J, Boersma M, Hagen W (2006) Trophodynamics and seasonal cycle of the copepod Pseudocalanus acuspes in the Central Baltic Sea (Bornholm Basin): evidence from lipid composition. Mar Biol 149:1417-1429

R Development Core Team (2009) R: a language and environment for statistical computing. $\mathrm{R}$ Foundation for Statistical Computing, Vienna

Renz J, Hirche HJ (2006) Life cycle of Pseudocalanus acuspes Giesbrecht (Copepoda, Calanoida) in the Central Baltic Sea. I. Seasonal and spatial distribution. Mar Biol 148:567-580

Editorial responsibility: Anna Pasternak, Moscow, Russian Federation
Renz J, Peters J, Hirche HJ (2007) Life cycle of Pseudocalanus acuspes Giesbrecht (Copepoda, Calanoida) in the Central Baltic Sea: II. Reproduction, growth and secondary production. Mar Biol 151:515-527

> Shenk TM, White GC, Burnham KP (1998) Sampling-variance effects on detecting density dependence from temporal trends in natural populations. Ecol Monogr 68: 445-463

Stepputtis D (2006) Distribution patterns of Baltic sprat (Sprattus sprattus L.) - causes and consequences. PhD dissertation, Christian-Albrechts-Universität $\mathrm{zu}$ Kiel, Kiel

> Stige LC, Lajus DL, Chan KS, Dalpadado P, Basedow SL, Berchenko I, Stenseth NC (2009) Climatic forcing of zooplankton dynamics is stronger during low densities of planktivorous fish. Limnol Oceanogr 54:1025-1036

> Strong DR, Frank KT (2010) Human involvement in food webs. Annu Rev Environ Resour 35:1-23

Twombly S, Wang GM, Hobbs NT (2007) Composite forces shape population dynamics of copepod crustaceans. Ecology 88:658-670

UNESCO (1979) Zooplankton sampling, Vol 2. UNESCO Press, Paris

Vidal J (1980a) Physioecology of zooplankton. 1. Effects of phytoplankton concentration, temperature, and body size on the growth rate of Calanus pacificus and Pseudocalanus sp. Mar Biol 56:111-134

> Vidal J (1980b) Physioecology of zooplankton. 2. Effects of phytoplankton concentration, temperature, and body size on the development and molting rates of Calanus pacificus and Pseudocalanus sp. Mar Biol 56:135-146

> Wasmund N, Uhlig S (2003) Phytoplankton trends in the Baltic Sea. ICES J Mar Sci 60:177-186

Wasmund N, Tuimala J, Suikkanen S, Vandepitte L, Kraberg A (2011) Long-term trends in phytoplankton composition in the western and central Baltic Sea. J Mar Syst 87:145-159

Wood SN (2000) Modelling and smoothing parameter estimation with multiple quadratic penalties. J R Stat Soc B Stat Methodol 62:413-428

Wood SN (2006) Generalized additive models: an introduction with R, Vol 1. Chapman \& Hall/CRC, Boca Raton, FL

- Worm B, Barbier EB, Beaumont N, Duffy JE and others (2006) Impacts of biodiversity loss on ocean ecosystem services. Science 314:787-790

Submitted: May 23, 2013; Accepted: October 17, 2013

Proofs received from author(s): January 20, 2014 